\title{
PREVALENCE OF STUDENTS WITH LEARNING DIFFICULTIES IN NUMBER CONCEPTS AT PRIMARY LEVEL IN PUNJAB
}

\author{
Muhammad Javed Aftab \\ Lecturer, \\ Department of Special Education, University of Education, \\ Punjab, Pakistan. \\ Email: drmjavedaftab@ue.edu.pk

\section{Muhammad Naeem} \\ Lecturer, \\ Department of English and General Studies, Kuwait technical college, \\ Abu Halifa, Kuwait \\ Email: m.naeem@k-tech.edu.kw

\section{Muhammad Ashfaq} \\ Assistant Professor, \\ Department of Special Education, University of Education, \\ Punjab, Pakistan. \\ Email: drashfaqch@gmail.com
}

\begin{abstract}
The aim of this research was to assess the prevalence of primary mathematics students with learning disabilities. For this cause, 2392 students were chosen as samples. A sample has been chosen. The term 'learning disability' is not an indication of the degree of intelligence, though, it indicates that students can experience physical, educational, emotional and environmental challenges. A review list was designed to classify students with statistical problems and to create a diagnosis test consisting of four subtests: 1 PNT, 2 new diagnostic test, authenticity of screen checklists, diagnostic examinations, and the appropriate field experts. The review list was developed. The evaluation list included a series of diagnostic assessments. Cronbach alpha coefficient of .83 and .80 , respectively, have determined the reliability of the screening checklist and diagnostic test. In order to interpret collected data, descriptive and inferential statistical methods were used. Independent sample Ttests were used to detect the gender, rural, low and high-performance differences between students. The incidence of mathematics comparatively higher for female students with learning disabilities compared to male primary students. The prevalence of men and women with learning disabilities was $15.4 \%$ and $20.2 \%$. The incidence of mathematical students is 15.6 percent. The training programme to develop capacity for mathematics
\end{abstract}


teachers at the primary level was strongly recommended. In addition, teachers need to use the activity based pedagogical skills to learn mathematics effectively and forever.

\section{KEYWORDS}

Prevalence, Number Concept, Learning Difficulties, Punjab, Primary Level,

\section{INTRODUCTION}

In terms of the subject matter, early mathematics is mostly numbered later on, the key component remains numbered in the various headings and new topics are added, such as measurement algebra and space topics. The requirements of math can therefore seem very large, and this can be quite helpful, but the numbers of early learning experiences can be excessive. Lack of skills may also be a contributing factor in dyscalculia. This might lead one to understand the correlation between the demands of the job and the learner's abilities.

Math may be a topic or a psychological exercise in terms of approach. The formula can be or it may be intuitive. It can be learned and conveyed in either way by the learner, or combined with the teacher's instruction and communication. Mathematics can be real, but it shifts very fast to symbolic and abstract. It's got a lot of rules and a lot of incoherence. Mathematics is very unique as a school topic in terms of judgement, input and assessment. Work is normally brutal or erroneous and must be accomplished rapidly.

The basic term "learning impairments" is used in those that have IQ levels in the normal range 90 to 120 , and because of disturbances in some psychological processes, in particular with regard to language, the causes of their impairments are considered internally. Nevertheless, in this review, the terms "learning disabilities" apply to this issue. Learning disorder does not mean that students have physical, education, emotional and environmental challenges, but it means that learning disability does not include intelligence. Instead of using the term "learning disability" the researcher suggests,' since both groups have the same educational intervention (having learning disabilities and learning difficulties).

Mathematical learning disabilities are a major concern. Mathematical learning difficulties generate learning challenges and impediments in ordinary school lessons. Different research papers found that Mathematics is difficult for many children (Ostad, 1998; Jordan, 2003; Ginsberg, 1977; Geary, 1993; Dowker, 2004, 2005).

Many reasons such as poor teaching skills, a rigid teaching style, a lack of interest in the technical field, inadequate use and use of instructional methods, inadvertent selection and use of audiovisual aids, lack of preparation, an inappropriate and 
irrelevant evaluation of mathematics is disclosed in research literature. Mathematics allows learners to study, gain insight and research about the world using powerful methods and tools. The ability to use differences in knowledge, to investigate relationships, to make similarities, to recognize differences and to establish relationships determines the importance of the topic in the academic years through the curriculum and curriculum. Mathematics is a problem that plays a complex role in our everyday life, enhancing rational intellectuality and intangibly thinking.

Mathematics is the obligatory subject for grades 1 to 10 in the national curriculum of Pakistan. For most pupils in public and private schools around the world mathematical learning isn't a straightforward process. The program provides very detailed information that requires a specific approach, a specific mentality (rational and systematic thinking), and student's struggle (Rojan, 2008; Ellis, 2011; Govt of Pakistan, 2006). However, teachers do not acquire the basic skills required for studying mathematics in both private and public schools. As a consequence, even after teaching in elementary or secondary schools, students cannot deal with mathematics (Government of Pakistan, 2009).

There is an absence of comprehensive and in-depth study of basic mathematics education in Pakistan, particularly in Punjab Province. The results of mathematical research investigations did not reflect the whole picture of secondary education and learning in this country. Some studies in primary school focus mainly on mathematics teaching, but there are no studies which focus on the learning problems of mathematics students.

In Pakistan, primary education in mathematics suffers from teachers' pedagogical expertise and student internalization of mathematical concepts. Teachers often cannot explain explicitly the idea of mathematics that increase the problems of students in studying mathematics. The goal of this survey was to figure out the prevalence of Punjab students who have difficulty studying primary mathematics with specific problems. The primary objective of this study is to determine how statistics are prevalent among students who have learning disabilities and to compare the frequency of learning difficulties in gender and local numbers.

\section{LITERATURE REVIEW}

Math is a creative language which allows people to think about the relationship and quantity aspect and to transmit ideas (Lerner and Johns, 2009, p. 478). Mathematics is Sidhu's discipline of number and space (1995). Awareness of size, amount and measurement is mathematics. The art of logical reasoning is also mentioned in mathematics. 
In numerical communities the infant with mathematical skills faces many particular cultural instruments (Butterworth, 2005a). These instruments include content learning skills and digital vocabulary, type identification, counting and granting. Abstract algebraic operations, data processing, geometry and measuring are also included (NCTM, 2000). It cannot be overlooked how important these tools are to construct basic mathematical concepts.

All people will react to the numeric features of their visual environment naturally 'without language, abstract logic or a great deal of chance in their world" (Butterworth, 2005a, p. 5). Butterworth (2005) refers to these tasks as some tasks that need certain answers. He states that a child's numbers are instinctive. Diverse experiments show that children respond to numbers between weeks of a few and 13 months (Antell \& Keating, 1983; Starkey and Cooper, 1980; Starkey, 1990; Brannon, 2002).

Any tests suggest that infants know the simple numbers, although they are 2 and can submit a range of items up to four or five (Strauss \& Curtis, 1981). Therefore, numerosity may be specified as an "invariant property for a number of objects specifying their numerical size" (Smitsman \& Van Loosbroek, 1990). The basis and the ladder are numerosity for mathematics and counting. Different scholars approached these two terms with various thoughts. Sousa (2008), for example, stipulates that mathematics is "capable of identifying, counting and doing basic addition and subtraction without direct instruction in the number of items in a small set". This concept is similar to Dowker's definition of numeracy (2004). (2004). (2004). I count items, iii) oral counts, (iii) writings and interpretations, (iv) units, tens and hundreds (v) ordinal numbers, (vi) word queries, (vii) data extracted, (viii) translation, (ix) assessments and $(\mathrm{x})$ documented text verification. The following are 10 constituents of its meaning.

Numerousness, which is instinctual, is thought to be an inventory ladder that enables mathematics to advance. Numerity means the primary talent in order to consider quantity, and Dowker cites numeracy as one or more of the ten elements of numeracy (2004). The term mathematics, on the other hand, alludes to a broader meaning of numeracy that encompasses data management, geometry, and other areas of NCTM (Chinn, 2004).

Dowker (2004) considers mathematics to be uncomplicated, since the data is treated, measured, geometric and much more diverse. The Department of Education and Skills have provided the same definition (DFES, 1999). The key 12 mathematical components that were defined by NCTM (National Mathematics Teacher Council), USA were presented by Chinn (2004). Chinn's report the following are: the communications of mathematical principles, problem solving and math's, application 
of math's in practice, knowledge of outcomes rationality, calculation, adequate numerical know-how, Knowledge, estimation, geometry, statistics and probability algebraic. This is most likely because children could not grasp at the beginning aspects of count reduction which were confronted by count reduction problems and mathematics later (Dowker, 2004).

Chinn (2004) stressed that "there are many reasons why people in the field of mathematics can achieve nothing" (p. 3). One aspect, however, may be a difference between all or some of the NCTM, USA skills, ideas and/or areas. "Not well known but well recognized are special learning disabilities in scoring" " (Butterworth, 2005a). Still in this arena, some research concentrates on challenging areas of students' numeracy. Certain students may have difficulties in all major areas of math; however, the majority are confused only in some fields of mathematics (Landerl, 2004), (Temple, 1991). Therefore, we should not classify the students as good or poor but rather resolve the problems in particular mathematical areas (Dowker, 2004). So, once they have been correctly recognized, it is really important to solve the issues they face.

The two ways to classify students with learning problems were stated by Lerner \& Johns (2015): 1) reaction to intervention with suspected problems or 2) a thorough assessment of students who have suspected learning problems.

Research studies have shown that most of the diagnostic tests are valid and are effective diagnostic instruments for diagnosing children in the fields of mathematics with learning disabilities who are in need of support. Research also focuses on the need for students with learning disabilities to understand the problem areas that must be lectured again in mathematics in the field.

IDEA (2006) explained that intervention response is a process used to classify students with learning disabilities when the students with learning difficulties encounter challenges for the first time. The primary purpose of responding to the intervention process to prevent academic failure (students who have learning problems, are at risk of a school breakdown and have minor disabilities), and is also used by all general education classrooms. Fuchs \& Vaughn (2012) stated that there are the three tiers of the RTI (Responses to Intervention) procedure. RTI is the most useful assessment method for screening students with reading and mathematics difficulty. RTI is used to teach students with learning difficulties more intensively. Those three phases comprise: (1) high quality education and student progress tracking, (2) increased evidence-based guidance, continuous monitoring of progress, and (3) high intensity and evidence-based action in small and/or individual classes, and continuous monitoring of progress. 
A systematic assessment is the second way to classify students with learning disabilities. The thorough assessment serves as a process to gather information about students suspected of being able to make judgements and important decisions about students suspected of having learning disabilities that can contribute to the development of effective instructions. The rigorous assessment tool the schools use to draw up a personalised learning plan for the students (Hallahan \& Cohen, 2008; Salvia, Yasseldyke, \& Bolt, 2007).

The systematic assessment contained a range of types of details, according to the Division of Learning Disabilities, 2007: student behaviour data; education-related medical findings; visual, listening or motor disabilities exclusion data, mental retardation, emotional distress, cultural causes, environmental or economic disadvantages, and little English competence. The student's ability to speak, read, write and spell; evidence-based recommendations; 6) RTI analysis, and a contrast between the student's academic ability and actual success are included.

Batsche, Kavale, \& Kovaleski (2009) stated in the comprehensive evaluation a discrepancy score is used to quantifying the discrepancy between the achievement and intellectual ability. There are several different formulas are used to calculate the discrepancy score. Discrepancy is considered as a reliable criterion. Students have categories on the basis on discrepancy score rather than the low achievement of the students.

No wonder why mathematics is also involved in many fields of adult life. Despite undeniable uses of the capital trade and different careers (McCloskey, 2007), mathematics impacts our support for recreations, such as fine art, knitting, cooking, card playing and adolescence sports. Sound developments in our daily lives in scientific intuition. Thus, low mathematical achievement has colossal long-term consequences.

Studies in research have shown that inadequate science in school years has an effect on young people and adulthood, an advantageous goal in advance is to consider that young children are at risk for poor mathematical achievement. A number of components can be considered when determining if such a danger may be expected. It must include understanding the difficulties of scientific learning, taking into account the many points of impact on the growth of numerical abilities and the specific paths along which any aspects of success are deemed correct. Whereas the only way to recognize which pre-school children are at risk of low numerical results is by no means fair responses, late research is helpful in further efforts. Early expectations will also raise the probability, even if the exam does not provide all the answers to appropriate caution and care, that child mathematical problems are diluted or maintained at 
strategic distances by pre-schedule intercession.

\section{RESEARCH METHODOLOGY}

Descriptive research design has been used to detect the prevalence of students in the mainstream government schools in Punjab who have facing difficulties in learning mathematics at primary level. This research is delimited to the Lahore district only.

\section{Population and Sampling}

The population for this study were all the students studying in fifth (05) grades primary schools of the province of Punjab. In all the public schools in the district the Lahore Department of Workers Development in Punjab has divided into 40 training and vocational training clusters for teachers in elementary schools. Geographic boundaries-based Lahore. Due to the district's geographical borders of Lahore, at least two schools were selected from each cluster. There were two classes, one for males and one for girls.

Number of Schools $=$ Total Number of Cluster $\times 2$

Number of Schools $=40 \times 2$

Number of Schools $=80$

Number of Students in grade five $(05)=19999$

DATA COLLECTION \& ANALYSIS

Demographics of Sample

Table 1: Frequency distribution of demograhics of sample in terms of the gender and the living area of the respondents (Students)

\begin{tabular}{lcc}
\hline Category & Frequency & Percent \\
\hline Male & 1161 & 48.53 \\
Female & 1231 & 51.47 \\
Rural & 1243 & 51.9 \\
Urban & 1149 & 48.1 \\
\hline
\end{tabular}

\section{Instrumentation}

For conducting this research, two research tools have been developed: 1) a checklist for screenings (SCLDM) managed by elementary school mathematics teachers in mainstream public schools. The students with anticipated learning disabilities must be completed by the teachers. 2) Number Diagnostic Test (NDT) consisting of 30 items related to number concepts from the curriculum issued by the Punjab text book board for the 5th grade. Number Diagnostic Test (NDT) consisting on the Multiple-Choice 
Questions (MCQs) of diagnostic nature relevant to the number concepts were included for identifying the students with learning difficulties in Mathematics.

Table 2: Research Tool Reliability

Cronbach's Alpha coefficient for the identification of reliability of the screening checklist and Number Diagnostic Test (NDT) for the students with learning difficutlies in number concepts in Mathematics

\begin{tabular}{lccc}
\hline Scale Factor & $\begin{array}{c}\text { No of } \\
\text { Respondents }\end{array}$ & No of Items & Coefficients \\
\hline Students Screening Checklist & 2392 & 30 & .82 \\
Number Diagnostic Test & 2392 & 30 & .80 \\
\hline
\end{tabular}

$* P<.05$ Level of Significance

Table 2 shows the reliability coefficient $\left(N=2392, N_{\text {Items }}=30, \alpha=.82\right)$ for the screening checklist deigned to screen out the suspected students with learning in number concepts skills in mathematics and the reliability coefficient for the Number Diagnostic Test (NDT) $\left(N=2392, N_{\text {Items }}=30, \alpha=.80\right)$ which developed to identify the students with learning diffiulties in the number concepts skills in mathematics at elementary level in the mainstream schools of the province of Punjab.

Table 3: Concurrent Validity

Concurrent Validity of Number Diagnostic Test (NDT) for students with learning difficultes in number concept skills in Mathematics

\begin{tabular}{lccc}
\hline Test / Correlation & $\begin{array}{c}\text { No. of } \\
\text { Items }\end{array}$ & $\begin{array}{c}\text { No. of } \\
\text { Students }\end{array}$ & $\begin{array}{c}\text { Correlation with } \\
\text { Achievement Test }\end{array}$ \\
\hline $\begin{array}{l}\text { Number Diagnostic } \\
\text { Test }\end{array}$ & 30 & 2392 & $.76^{* *}$ \\
\hline$* * P<.05$ Level of significance & &
\end{tabular}

Table 3 shows that the empirical information $\left(N=2392, N_{\text {Items }}=30, \alpha=.76^{* *}\right)$ of concurrent validity of the Number Diagnostic Test (NDT) which leads to the decision that there is strong positiv correlation between the Number Diagnostic Test (NDT) and the achievement of the students in the subject of Mathematics.

In order to collect data from selected sample of student studying in fifth grade by using the tools developed by the researcher himself. Basically, two tools were developed for this purpose of identification i.e., 1) screening checklist and 2) number diagnostic test. Both instruments were individually used for the 5th grade student (the diagnosis test and the screening checklist). The researcher himself gave the checklist to the teachers in public schools, who taught mathematics in fifth classes. Teachers have a day to 
make suggestions about students' academic difficulties in mathematics. After acknowledging that students had expected learning difficulties in the area of mathematics, the researchers focused for the diagnostic test to grade 05 students. Instructions have been officially exchanged for solving the test under the supervision of the researcher.

Data from the instruments described above were obtained and analyzed using the Statistical Package for Social Science (SPSS). Descriptive and inferential statistical treatment were applied on the collected data. Descriptive statistical treatment were provided the frequency and percentage results of the students responses which will lead to decision about the identification of the students with learning difficulties.

Table 4: Frequency Distribution of responses of the respondents at Number Diagnostic Test (NDT)

\begin{tabular}{cccccccccc}
\hline \multirow{2}{*}{$\begin{array}{c}\text { Sr. } \\
\text { No }\end{array}$} & Item & \multicolumn{2}{c}{ Correct } & \multicolumn{2}{c}{ Wrong } & \multicolumn{2}{c}{$\begin{array}{c}\text { Not } \\
\text { Responded }\end{array}$} & \multicolumn{2}{c}{ Total } \\
\cline { 3 - 10 } & & $\boldsymbol{f}$ & $(\boldsymbol{\%})$ & $\boldsymbol{f}$ & $(\boldsymbol{\%})$ & $\boldsymbol{f}$ & $(\boldsymbol{\%})$ & $\boldsymbol{f}$ & $(\boldsymbol{\%})$ \\
\hline 1 & $\mathrm{~N} .1$ & 1238 & $(51.76)$ & 1027 & $(42.93)$ & 127 & $(5.31)$ & 2392 & $(100)$ \\
2 & N.2 & 686 & $(28.68)$ & 1555 & $(65.01)$ & 151 & $(6.31)$ & 2392 & $(100)$ \\
3 & N.3 & 242 & $(10.12)$ & 2027 & $(84.74)$ & 123 & $(5.14)$ & 2392 & $(100)$ \\
4 & N.4 & 1400 & $(58.53)$ & 893 & $(37.33)$ & 99 & $(4.14)$ & 2392 & $(100)$ \\
5 & N.5 & 902 & $(37.71)$ & 1323 & $(55.31)$ & 167 & $(6.98)$ & 2392 & $(100)$ \\
6 & N.6 & 506 & $(21.15)$ & 1711 & $(71.53)$ & 175 & $(7.32)$ & 2392 & $(100)$ \\
7 & N.7 & 914 & $(38.21)$ & 1247 & $(52.13)$ & 231 & $(9.66)$ & 2392 & $(100)$ \\
8 & N.8 & 900 & $(37.56)$ & 1309 & $(54.63)$ & 187 & $(7.80)$ & 2396 & $(100)$ \\
9 & N.9 & 1174 & $(49.08)$ & 1067 & $(44.61)$ & 151 & $(6.31)$ & 2392 & $(100)$ \\
10 & N.10 & 1162 & $(48.58)$ & 1021 & $(42.68)$ & 209 & $(8.74)$ & 2392 & $(100)$ \\
\hline
\end{tabular}

Table 4 indicates that the students 1238 (51.76\%), 686(28.68\%), 242(10.12\%), $1400(58.53 \%), \quad 902(37.71 \%), \quad 506(21.15 \%), \quad 914(38.21 \%), \quad 900(37.56 \%)$, $1174(49.08 \%), 1162(48.58 \%)$ were answered correctly to the items N.1, N.2, N.3, N.4, N.5, N.6, N.7, N.8, N.9, and N.10 respectively. Table 4 indicates that the students $1027(42.93 \%), \quad 1555(65.01 \%), 2027$ (84.74\%), 893(37.33\%), 1323(55.31\%), $1711(71.53 \%), 1247(52.13 \%), 1309(54.63 \%), 1067(44.61 \%)$, and 1021(42.68\%) were responded wrong to the items N.1, N.2, N.3, N.4, N.5, N.6, N.7, N.8, N.9, and N.10 respectively.

Table 4 indicates that the students 127(5.31\%), 151(6.31\%), 123(5.14\%), 100(4.14\%), 
167(6.98\%), 175(7.32\%), 231(9.66\%), 187(7.80\%), 151(6.31\%), and $209(8.74 \%)$ were not responded to the items N.1, N.2, N.3, N.4, N.5, N.6, N.7, N.8, N.9, and N.10 respectively.

Table 5: Prevalence of primary level students with learning difficulties in the number concepts skills in Mathematics

\begin{tabular}{cccc}
\hline $\begin{array}{c}\text { Conceptual } \\
\text { Areas } \\
\text { /Mathematical } \\
\text { skills }\end{array}$ & $\begin{array}{c}\text { Total No. of } \\
\text { students } \\
\text { assessed }\end{array}$ & $\begin{array}{c}\text { No. of students } \\
\text { with learning } \\
\text { difficulties }\end{array}$ & $\begin{array}{c}\text { Prevalence of } \\
\text { students with } \\
\text { learning difficulties }\end{array}$ \\
\hline $\begin{array}{c}\text { Number } \\
\text { Concepts }\end{array}$ & 2392 & 384 & $384 / 2392 \times 100 \%=$ \\
$16 \%$
\end{tabular}

$* P<.05$ Level of Significance

Table 5 specifies the empirical information $(384(16 \%), * \mathrm{P}<.05)$ of students out of 2392 significantly prevailed with learning difficulties in number concepts skills in mathematics at primary level.

Table 6: Prevelance of female primary level students with learning difficulties in number concepts skills in mathematics

\begin{tabular}{cccc}
\hline $\begin{array}{c}\text { Conceptual } \\
\text { Areas } \\
\text { Mathematical } \\
\text { skills }\end{array}$ & $\begin{array}{c}\text { Total No. of } \\
\text { students } \\
\text { assessed }\end{array}$ & $\begin{array}{c}\text { No. of students } \\
\text { with learning } \\
\text { difficulties }\end{array}$ & $\begin{array}{c}\text { Prevalence of } \\
\text { students with } \\
\text { learning difficulties }\end{array}$ \\
\hline $\begin{array}{c}\text { Number } \\
\text { Concepts }\end{array}$ & 2392 & 223 & $223 / 2392 \times 100 \%=$ \\
$19.2 \%$
\end{tabular}

$* P<.05$ Level of Significance

Table 6 illustrates that the empirical information $(223(19.2 \%), * \mathrm{P}<.05)$ of female students out of 2392 significantly prevailed with learning difficulties in number concepts skills in mathematics at primary level.

Table 7: Prevelance of male primary level students with learning difficulties in number concepts in mathematics

\begin{tabular}{cccc}
\hline $\begin{array}{c}\text { Conceptual } \\
\text { Areas } \\
\text { /Mathematical } \\
\text { skills }\end{array}$ & $\begin{array}{c}\text { Total No. of } \\
\text { students } \\
\text { assessed }\end{array}$ & $\begin{array}{c}\text { No. of students } \\
\text { with learning } \\
\text { difficulties }\end{array}$ & $\begin{array}{c}\text { Prevalence of } \\
\text { students with } \\
\text { learning difficulties }\end{array}$ \\
\hline $\begin{array}{c}\text { Number } \\
\text { Concepts }\end{array}$ & 2392 & 180 & $\begin{array}{c}180 / 2392 \times 100 \%= \\
14.6 \%\end{array}$ \\
\hline \hline
\end{tabular}


$* \mathrm{P}<.05$ Level of Significance

Table 7 illustrates that the empirical information $(180(14.6 \%)$, $* \mathrm{P}<.05)$ of male students out of 2392 significantly prevailed with learning difficulties in number concepts skills in mathematics at primary level.

Table 8: Comparison of Prevalence of Primary level Students with learning difficulties in number concepts in Mathematics

\begin{tabular}{lccccc}
\hline Groups & $\boldsymbol{N}$ & $\boldsymbol{M}$ & $\boldsymbol{d} \boldsymbol{f}$ & $\boldsymbol{t}$ & $\boldsymbol{S} \boldsymbol{i g}$ \\
\hline Male & 1161 & 31.96 & 1904 & 7.725 & .000 \\
Female & 1231 & 30.16 & 1268 & & \\
\hline
\end{tabular}

$* P<.05$ Level of Significance

Table 8 indicates that the empirical information for male $(N=1161, M=31.96$, S.D. $=)$ and for female $(N=1231, M=30.16, S . D .=)$ with t-statistics $(t(1904)=7.725, \mathrm{P}<.05$ $=.000$ ) which leads to the decision that there is a significant difference in the prevalence of primary level students regarding the learning difficulties in the number concepts in mathematics on the basis of gender (male/female). Moreover, it reveal that female have facing more learning difficulties as compared to the male students.

Table 9: Comparison of respondent's degree to mathematical learning problems in number diagnostic test based on a living environment

\begin{tabular}{cccccc}
\hline Living Area & $\boldsymbol{N}$ & $\boldsymbol{M}$ & $\boldsymbol{D} \boldsymbol{f}$ & $\boldsymbol{t}$ & $\boldsymbol{S} \boldsymbol{i g}$ \\
\hline Rural & 1243 & 53.76 & 1372 & 1.127 & .006 \\
Urban & 1149 & 55.36 & 1460 & & \\
\hline
\end{tabular}

$* P<.05$ Level of Significance

Table 9 illustrates that the empirical information for rural students $(N=1243, M=$ 53.76, S.D. $=5.10)$ and for urban students $(N=1149, M=55.36, S . D .=6.01)$ with $\mathrm{t}-$ statistics $(t(1372)=1.127, \mathrm{P}<.05=.006)$ which leads to the decision that there is a significant difference in the prevalence of primary level students regarding the learning difficulties in the number concepts in mathematics on the basis of their residential areas (rural/urban). Moreover, it reveal that rural students have facing more learning difficulties as compared to the urban students.

\section{RESEARCH FINDINGS}

The internal accuracy of the test items had an agreed set of alpha coefficients for all 
the samples. The pre number correlation, count definitions, Arithmetical operation diagnostic testing and geometry diagnostic testing are, respectively, $.43, .56, .60$ and.49, which are the acceptable level of association between basic test performance and primary mathematics achievement of pupils. Statistically significant was the degree of achievement among students in the pre-number diagnostic test and the diagnostic number test, the arithmetic operational test and the geometry diagnostic test.

The students' prenumerics and number concepts on the basis of their living conditions indicate a substantial difference in learning difficulties, showing that urban students have a clear intellectual history of preconcepts in terms of mathematical concepts, compared with those who live in urban areas. After the analysis of the data for the study in question was reviewed, it was noted that many grey areas had occurred such as prenium, number concepts, numerical detection, arithmetical (addition, subtraction, propagation \& division), fundamental geometrical shapes, angle detection, angle forms and math geometry, of which the students had difficulty understanding. The various researchers have also endorsed this idea. The psychologist from education Ormrod (2000) said that most students would probably be more confused than any other topic of the educational curriculum with the cause of mathematics. Especially because of the sequential and hierarchical definition of mathematical education, a student with no early concepts and skills is bound to have more and more problems because new and more challenging material is constantly being added to the subject of mathematics. Students with learning difficulties in mathematics prefer to give up all trust in understanding what algebra is and to keep memory of data, tools, symbols and processes that are meaningless. Not unexpectedly, the share of these students often takes a very pessimistic look at the subject of mathematics and improves their mathematical education dilemma scenario (Bhardwaj, 1987).

\section{DISCUSSION}

Mathematics is a hierarchy and series in which various ideas and capabilities are interlinked and original concepts and skills form the basis for further learning. There could be an inadequate programme behind students facing learning disabilities in the field of mathematics which does not correspond with the students' developmental stages. It should be changed in accordance with the phases of growth recommended by psychologists and curriculum professionals.

Poor standard instruction and instruction may be one of the causes of learning problems for students in mathematics at primary school. The teacher's understanding of the subject, which is incredibly poor in most primary schools, is the key element of the course. Primary teachers, in fact, have very limited understanding of the matter of mathematics (Shashikala Devi, 1987). 
The teacher's pedagogical qualifications, which play a crucial role in the student's learning, may be questionable with regard to the ability level. Teachers do not use visual aids and concrete materials to create ideas and capabilities (Mishra, 1998).

There could be no interactive classroom instruction with a high student attendance. Teachers don't have enough inservice education to help students develop skills and apply knowledge to students' practical life. Because of this shortcoming, links between mathematical knowledge and problems in real life cannot be formed.

It is also a major fact that there are some 58,000 primary teachers who teach mathematics at the primary school level for various grades and subjects. These teachers work with the Matric/PTC qualification (DSD, Reports March 2016). In this modern era, new curricula, pedagogy, new methods and standards frequently do not upgrade their qualifications to the various primary levels in the area of mathematics. In brief, the inadequate teaching of mathematics at the primary level may be a cause for learning difficulties.

Teachers in the 5th grade at primary level may not have adequate experience in the field of mathematics teaching. The lack of continuous vocational development is one reason why students encounter learning challenges at elementary level in the field of mathematics (Steele, 2006).

In comparison to other competences such as count concepts, arithmetic number operation and geometry concept that is caused by rotate learning of the Kothari students, the prevalence of students in prenumber concepts is greater (1985).

In the field of mathematics, the prevalence of women is $20,2 \%$ and $15,4 \%$ respectively, compared with male students. The explanation may be that female students have a negative attitude towards the topic of mathematics, backed by various research studies. Study also supports male naturally in math (http://gender.stanford.edu/news/), better than female in mathematics. In addition, the woman is less rational than the guy (www.quora.com).

The performance of students in rural and urban suburban areas is significantly different. PeiAn Liao, HungHao Chang, JiunHao Wang and TaiHsiung Horng (2013) have recorded a poor performance of rural students compared with urban students. The cause may be environmental factors, lack of services, education, interactions with people, qualifications for teachers, reduced communication with advanced communities, etc. Jeff, David McCracken. David T. Barcinas (1991) has indicated that urban and rural students have a significant gap in performance, while rural students score less than urban students. This can be attributed to low-income groups, disparity 
in the relationship between communities and schools, teacher qualifications, and the number of facilities etc.

\section{RECCOMENDATIONS}

It is recommended that more testing at macro level in accordance with this analysis is recommended at primary, secondary and high school classes, and that the designed diagnostic technique is used by teachers in various areas of mathematics to identify learning disabilities. Because girls have more mathematical problems and difficulties, the teacher should work on them intentionally. Rural schools need physical and pictorial representations, including graphs or handson products, to include students with disabilities of mathematics to integrate mathematical principles.

\section{REFERENCES}

Butterworth, B. (1999). The Mathematical Brain. London: Macmillan

Bhardwaj, R. P. (1987). Standardization of a Comprehensive Diagnostic Test \& Preparation of Remedial Material in Mathematics for Middle Standard Students of Haryana. Ph.D. (Edu.), Kurukshetra University. In M. B. Buch (Ed. 1991) Fourth Survey of Research In Education. New Delhi: NCERT.

Chinn, S \& Ashcroft, R. (2007). Mathematics for Dyslexics Including Dyscalculia. Australia: John Wiley \& Sons, Ltd.

Chinn, S. (2004). The trouble with math: A practical guide to helping learners with numeracy difficulties. London \& New York: Routledge Falmer Taylor \& Francis Group.

Cohen, L., Manion, L\&Morrion, K. (2007). Research Methods in Education. New York: Open University.

Creswell, J.W. (2012). Educational Research Planning, conducting and Evaluating Quantitative and Qualitative Research ( $4^{\text {th }}$ Ed). New York \& London: Pearson

Dowker, A. (2007). Mathematical Difficulties Psychology and Intervention. London: Jessica Kingsley Publishers.

Dowker, A. Mathematical Difficulties Psychology and Intervention. London: Routledge

Dowker, A. (2005a). Early identification and intervention for students with mathematics difficulties. Journal of Learning Disabilities, 38, 324332

Dowke r, A. (2005b). Individual Difference in Arithmetic: Implications for psychology, Neuroscience, and Education. Hovw and New York: Psychology Press.

Fuchs, L. S., Compton, D. L., Fuchs, D., Paulsen, K., Bryant, J. D., \& Hamlett, C. L. 286 References (2005). The prevention, identification, and cognitive determinants of math difficulty. Journal of Educational Psychology, 97, 493-513.

Gay, L. R. (2000). Educational Research: Competencies for Analysis and Application. Islamabad: Allama Iqbal Open University.

Geary, D.C. (1993). Mathematical disabilities: cognition, neuropsychological and genetic components. Psychological Bulletin, 114, 34562.

Geary, D.C, Hamson, C.O., \& Hoard. M.K. (2000) Numerical and arithmetical cognition: A longitudinal study of process and concept deficits in children with learning 
disability. Journal of Experimental Child Psychology 77,236-263.

Geary, D. C. (1993). Mathematical disabilities: Cognitive, neuropsychological, and genetic components. Psychological Bulletin. 114, 345362.

Gersten, R., Jordan, N.C., \& Flojo, J.R. (2005). Early identification and interventions for children with mathematics difficulties. Journal of Learning Disabilities, 38, 293-304.

Kothari, C. (2004). Research Methodology Methods and Techniques. New Delhi: New Age International Publishers.

Kothari, R. G. (1985). An Investigation into Efficacy of Different Instructional Media in The teaching of Mathematics to the Pupils of Class IX in Relation to Certain Variables. An Unpublished Ph.D. (Edu.) thesis. Vidyanagar: Sardar Patel University.

Kavale, K. A. (2002). History, rhetoric, and reality. Remedial \& special Education, 21(5), 279

Lerner, A.W \& Johns, B. H. (2015). Learning Disabilities and Related Disabilities: trategies for Success. United States: Cengage Learning

Mishra, S. (1998). A Study on the Effective Use of the OB Materials and Other TLM to adopt joyful and activitycentered learning in mathematics in classes I to III. Research Abstracts in Primary Education (19942000). New Delhi: Educational Consultants India Ltd.

Shelly, D. \& Cohen, D. (1996). Testing Educational Tests. London. Croam Helin.

Shashikala Devi, U. (1987). An Analytical Study of Effective Mathematics Teaching. An Unpublished Ph.D. (Edu.) thesis. Vadodara: CASE, The Maharaja Sayajirao University of Baroda,

Steele, M. (2006). Middle Grades Geometry and Measurement: Examining Change in Knowledge needed for Teaching through Practice based Teaching Education Experience. Ed.D., University of Pittsburgh. Dissertation Abstract International, 67(6), 2086A.

Van Hiele, P. (1986) Structure and insight. A theory of mathematics Education. NY: Academic press. 